\title{
Modeling Phosphorus Capture by Plants Growing in a Multispecies Riparian Buffer
}

\author{
J. M. Kelly' and J. L. Kovar ${ }^{2}$ \\ ${ }^{1}$ College of Natural Resources and Environment, Virginia Tech, 324 Cheatham Hall, Blacksburg, VA 24060, USA \\ ${ }^{2}$ National Laboratory for Agriculture and the Environment, USDA-Agricultural Research Service, 2110 University Boulevard, \\ Ames, IA 50011, USA
}

Correspondence should be addressed to J. M. Kelly, jmkelly@vt.edu

Received 17 February 2012; Accepted 20 May 2012

Academic Editor: Artemi Cerda

Copyright ( $) 2012$ J. M. Kelly and J. L. Kovar. This is an open access article distributed under the Creative Commons Attribution License, which permits unrestricted use, distribution, and reproduction in any medium, provided the original work is properly cited.

The NST 3.0 mechanistic nutrient uptake model was used to explore P uptake to a depth of $120 \mathrm{~cm}$ over a $126 \mathrm{~d}$ growing season in simulated buffer communities composed of mixtures of cottonwood (Populus deltoids Bartr.), switchgrass (Panicum virgatum L.), and smooth brome (Bromus inermis Leyss). Model estimates of P uptake from pure stands of smooth brome and cottonwood were 18.9 and $24.5 \mathrm{~kg} \mathrm{ha}^{-1}$, respectively. Uptake estimates for mixed stands of trees and grasses were intermediate to pure stands. A single factor sensitivity analysis of parameters used to calculate $\mathrm{P}$ uptake for each cover type indicated that $I_{\max }, k, r_{o}$, and $L_{o}$ were consistently the most responsive to changes ranging from $-50 \%$ to $+100 \%$. Model exploration of $\mathrm{P}$ uptake as a function of soil depth interval indicated that uptake was highest in the $0-30 \mathrm{~cm}$ intervals, with values ranging from $85 \%$ of total for cottonwood to $56 \%$ for switchgrass.

\section{Introduction}

The loss of P from agricultural lands has been a subject of growing interest in the environmental community for the past two decades. The shift in regulatory focus in the latter half of the 1990s from point sources to diffuse sources and the associated requirement that total maximum daily load (TMDL) estimates be developed has led to the extensive use of a variety of $\mathrm{P}$ transport models to describe both particulate and solution phase movement of $\mathrm{P}[1,2]$.

Paralleling the evolution of $\mathrm{P}$ transport models has been the development and implementation of various types of riparian buffers intended to retard the movement of $\mathrm{P}$ to surface waters $[3,4]$. Buffers can significantly reduce particulate $\mathrm{P}$ entering surface waters [5]. Control of dissolved $\mathrm{P}$ inputs is more challenging [6]. Given that plant roots remove P from soil solution, it follows that plant uptake (mining) can reduce losses of dissolved P to some extent as noted by van der Salm et al. [7].

In an earlier study, Kelly et al. [8] investigated the ability of various plant cover types to capture P from a loess soil in Western Iowa over a four-year period. By the end of the study period the four vegetation cover types exhibited differences in the amount of $\mathrm{P}$ incorporated into standing biomass. Given that there are likely differences in plant uptake of $\mathrm{P}$ as a result of cover type and soil conditions, it could prove useful to the TMDL process to have a means of mechanistically projecting vegetative uptake of $\mathrm{P}$ under a variety of conditions.

As noted by Claassen and Steingrobe [9], a validated mechanistic nutrient uptake model provides a means to extrapolate plant response beyond currently available data, as well as to evaluate potential hypotheses. In a recent review Hinsinger et al. [10] concur with the above statement and further discuss both the utility and efficacy of mechanistic models to describe P uptake. The NST 3.0 model [11] and its predecessor the Barber Cushman model $[12,13]$ have been used with a high degree of success to explore nutrient uptake under a variety of circumstances $[9,14]$. NST 3.0 provides a means to simulate the impacts of changes in both plant and soil processes on the uptake of $\mathrm{P}$ for a variety of plant species. In a recent study Lin and Kelly [15] found that NST 
3.0 provided the best estimates of $\mathrm{P}$ uptake in a three-model comparison utilizing a common set of input values.

The first objective of this study was to use the NST 3.0 model to explore the uptake of $\mathrm{P}$ to a depth of $120 \mathrm{~cm}$ over a single growing season in simulated buffer communities composed of varying percentages of cottonwood, switchgrass, and smooth brome; three plant species commonly used in riparian buffers in the Midwestern U.S. The second objective was to use the model to explore the impacts of changes in key soil supply and plant parameters, as determined by sensitivity analysis, on estimates of $\mathrm{P}$ uptake by the three test species. And finally, the third objective was to use the model to explore potential $\mathrm{P}$ capture from each of three soil depth increments $(0-30,30-60$, and 60-120 cm) over a 126-d growing season. The buffer species tend to be deeprooted, so we hypothesized that $\mathrm{P}$ uptake from subsoil could be significant.

\section{Materials and Methods}

The NST 3.0 model was used to make all the calculations in this study. It is a transient model that requires numerical solution. The model along with necessary documentation is available for download from the website of the Department of Crop Sciences at Göttingen University (http://wwwuser.gwdg.de/ uaac/download.htm). In order to operate, the model requires the user to provide information describing: (i) the availability of water and the ability of the soil to supply the nutrient of interest, (ii) the beginning length and growth rate of the root system, and (iii) a suite of values describing the uptake of the nutrient at the root surface, utilizing Michaelis-Menten kinetics. The required parameters along with numerical values for each parameter for each of the three plant cover types investigated are listed by depth interval in Tables 1,2 , and 3 . These values were obtained from samples collected and measurements made in support of the study described by Kelly et al. [8] and from related studies conducted by Kovar and Claassen [16] and Kelly and Ericsson [17]. As described by Kelly et al. [8] the study site was divided into five $22 \times 20 \mathrm{~m}$ blocks. The number of samples collected varied by parameter but in all cases sample size was sufficient to provide representative mean values. Data for this analysis were taken from the 2003 growing season.

\subsection{Determination of Parameters Describing P Uptake Kinet-} ics. A solution depletion technique using intact plants and transient conditions, as described by Claassen and Barber [19] and Edwards and Barber [20] was used to determine the Michaelis-Menten $\mathrm{P}$ uptake kinetics values $I_{\max }$ (maximum influx at high concentrations), $K_{m}$ (nutrient concentration in solution when influx is one-half of $I_{\max }$ ), and $C_{\min }$ (concentration in solution below which influx ceases) needed to run the NST 3.0 model.

For smooth brome, the depletion study was conducted at $49 \mathrm{~d}$ after germination and for switchgrass the plants were $54 \mathrm{~d}$ after germination [16]. Initial solution $\mathrm{P}$ concentration for both studies was approximately $50 \mu \mathrm{mol} \mathrm{L}^{-1}$. In both cases, samples were collected at $30 \mathrm{~min}$ intervals and $C_{\min }$ was achieved at approximately $14 \mathrm{hr}$.

The cottonwood depletion study followed procedures described in Kelly and Ericsson [17] using green-stem single node cuttings. The cuttings were allowed to grow for $48 \mathrm{~d}$ prior to initiating the depletion study. Initial solution $\mathrm{P}$ concentration was approximately $7 \mu \mathrm{mol} \mathrm{L}^{-1}$. Samples were collected at $15 \mathrm{~min}$ intervals until the solution concentration reached the minimum root uptake at approximately $12 \mathrm{hr}$.

2.2. Determination of Parameters Describing Root Growth. A field study was used to obtain estimates of the mean half-distance between roots $\left(r_{1}\right)$, mean root radius $\left(r_{o}\right)$, initial root length $\left(L_{o}\right)$, and root growth rate $(k)$. A tractormounted hydraulic probe (Giddings Machine Co., Inc.; Windsor, CO) was used to collect $5.0 \mathrm{~cm}$ diameter root sample cores to a depth of $120 \mathrm{~cm}$. Details of the field sampling procedures used to collect the cottonwood, switchgrass, and smooth brome buffer segments can be found in Kelly et al. [8]. Sample cores were dispersed in tap water and the roots collected using methods described by Kelly and Ericsson [17]. Total root length of each sample was then determined using the line intercept method of Tennant [21]. Mean root radius was calculated based on the fresh weight using the method described by Mackay and Barber [22].

\subsection{Determination of Parameters Describing Soil Supply of} $P$. Soil samples collected at the start of the 2003 growing season were used to determine the solution and solid phase $\mathrm{P}$ concentrations in the soil. Soil solution was collected using the displacement column procedure described by Kovar and Barber [23] followed by ICP analysis of P concentration as described by Clesceri et al. [24]. For the solid phase determination, soil samples were air-dried and extractable $\mathrm{P}\left(0.025 \mathrm{M} \mathrm{HCl}\right.$ in $\left.0.03 \mathrm{M} \mathrm{NH}_{4} \mathrm{~F}\right)$ was determined by ICP analysis [25]. Solution and solid phase $\mathrm{P}$ concentrations were then used to calculate the effective diffusion coefficient $\left(D_{e}\right)$, buffer power $(b)$, and initial equilibrium solution concentration $\left(C_{\mathrm{li}}\right)$ according to the procedures described by Kelly et al. [26].

2.4. Model Simulation Procedures. Preliminary model runs were made using the $0-120 \mathrm{~cm}$ values listed in Tables 1,2 , and 3 for each species, with the exception that the $I_{\max }$ values for each species were adjusted from the experimentally derived values to a level that would provide a model calculated uptake equivalent to the observed uptake based on field measurements. This generally required that the $I_{\max }$ value is adjusted downward by an order of magnitude using the approach described in Kelly et al. [27]. The simulation ran for a period of 126 days, the time between the initial harvest in early May and the final harvest in late September.

To explore model results further, a series of single factor sensitivity analyses were conducted with the $0-120 \mathrm{~cm}$ and 0-30 $\mathrm{cm}$ data using the approach described by Silberbush and Barber [28]. Working from the base case scenario, each parameter value in the model was adjusted in turn to three different levels; $0.5,1.5$, or 2.0 times the base case value, while 
TABLE 1: Transport, sorption, and root parameters used in the NST 3.0 model to describe P uptake by cottonwood for the 0-120, 0-30, $30-60$, and $60-120 \mathrm{~cm}$ soil depths.

\begin{tabular}{|c|c|c|c|c|c|c|}
\hline \multicolumn{2}{|c|}{ Parameter } & Units & $0-120 \mathrm{~cm}$ & $0-30 \mathrm{~cm}$ & $30-60 \mathrm{~cm}$ & $60-120 \mathrm{~cm}$ \\
\hline$D_{e}$ & Diffusion coefficient in water ${ }^{\dagger}$ & $\mathrm{cm}^{2} \mathrm{~s}^{-1}$ & $8.9 E-6$ & $8.9 E-6$ & $8.9 E-6$ & $8.9 E-6$ \\
\hline$\Theta$ & Volumetric soil water content & $\mathrm{cm}^{3} \mathrm{H}_{2} \mathrm{O} / \mathrm{cm}^{3}$ soil & 0.32 & 0.32 & 0.33 & 0.31 \\
\hline$f$ & Impedance factor & Unitless & 0.33 & 0.33 & 0.35 & 0.32 \\
\hline$V_{o}$ & Water uptake at root & $\mathrm{cm} \mathrm{s}^{-1}$ & $7.45 E-7$ & $7.45 E-7$ & $7.45 E-7$ & $7.45 E-7$ \\
\hline$C_{\mathrm{li}}$ & Initial solution concentration & $\mu \mathrm{mol} \mathrm{cm}-3$ & $9.39 E-3$ & $2.69 E-2$ & $6.45 E-4$ & $6.45 E-4$ \\
\hline$b$ & Buffer power & Unitless & 314 & 45 & 477 & 421 \\
\hline$I_{\max }$ & Maximum influx at high concentration & $\mu \mathrm{mol} \mathrm{cm}{ }^{-2} \mathrm{~s}^{-1}$ & $1.64 E-8$ & $1.647 E-8$ & $1.647 E-8$ & $1.647 E-8$ \\
\hline$K_{m}$ & Solution concentration when influx is $0.5 I_{\max }$ & $\mu \mathrm{mol} \mathrm{cm}-3$ & $8.7 E-4$ & $8.7 E-4$ & $8.7 E-4$ & $8.7 E-4$ \\
\hline$C_{\min }$ & Solution concentration when influx is zero & $\mu \mathrm{mol} \mathrm{cm}^{-3}$ & $1.0 E-6$ & $1.0 E-6$ & $1.00 E-6$ & $1.00 E-6$ \\
\hline$r_{o}$ & Root radius & $\mathrm{cm}$ & 0.023 & 0.0241 & 0.0217 & 0.0217 \\
\hline$r_{1}$ & Half distance & $\mathrm{cm}$ & 1.05 & 0.213 & 0.378 & 2.578 \\
\hline$L_{o}$ & Initial root length & $\mathrm{cm} \mathrm{m}^{-3}$ & $3,041,322$ & $2,094,524$ & 663,672 & 283,126 \\
\hline$k$ & Root growth rate & $\mathrm{cm} \mathrm{d}^{-1}$ & 4,812 & 6,631 & 6,816 & 991 \\
\hline
\end{tabular}

${ }^{\dagger}$ From Edwards and Huffman [18].

TABLE 2: Transport, sorption, and root parameters used in the NST 3.0 model to describe P uptake by switchgrass for the 0-120, 0-30, 30-60, and $60-120 \mathrm{~cm}$ soil depths.

\begin{tabular}{|c|c|c|c|c|c|c|}
\hline \multicolumn{2}{|c|}{ Parameter } & Units & $0-120 \mathrm{~cm}$ & $0-30 \mathrm{~cm}$ & $30-60 \mathrm{~cm}$ & $60-120 \mathrm{~cm}$ \\
\hline$D_{e}$ & Diffusion coefficient in water ${ }^{\dagger}$ & $\mathrm{cm}^{2} \mathrm{~s}^{-1}$ & $8.9 E-6$ & $8.9 E-6$ & $8.9 E-6$ & $8.9 E-6$ \\
\hline$\Theta$ & Volumetric soil water content & $\mathrm{cm}^{3} \mathrm{H}_{2} \mathrm{O} / \mathrm{cm}^{3}$ soil & 0.37 & 0.39 & 0.36 & 0.36 \\
\hline$f$ & Impedance factor & Unitless & 0.42 & 0.45 & 0.40 & 0.40 \\
\hline$V_{o}$ & Water uptake at root & $\mathrm{cm} \mathrm{s}^{-1}$ & $8.43 E-7$ & $8.43 E-7$ & $8.43 E-7$ & $8.43 E-7$ \\
\hline$C_{\mathrm{li}}$ & Initial solution concentration & $\mu \mathrm{mol} \mathrm{cm}{ }^{-3}$ & $1.28 E-2$ & $2.95 E-2$ & $4.52 E-3$ & $4.52 E-3$ \\
\hline$b$ & Buffer power & Unitless & 63 & 47 & 74 & 69 \\
\hline$I_{\max }$ & Maximum influx at high concentration & $\mu \mathrm{mol} \mathrm{cm}{ }^{-2} \mathrm{~s}^{-1}$ & $2.30 E-8$ & $2.30 E-8$ & $2.30 E-8$ & $2.30 E-8$ \\
\hline$K_{m}$ & Solution concentration when influx is $0.5 I_{\max }$ & $\mu \mathrm{mol} \mathrm{cm}-3$ & $3.22 E-5$ & $3.22 E-5$ & $3.22 E-5$ & $3.22 E-5$ \\
\hline$C_{\min }$ & Solution concentration when influx is zero & $\mu \mathrm{mol} \mathrm{cm}{ }^{-3}$ & $102 E-6$ & $1.02 E-6$ & $1.02 E-6$ & $1.02 E-6$ \\
\hline$r_{o}$ & Root radius & $\mathrm{cm}$ & 0.009 & 0.0121 & 0.0075 & 0.0085 \\
\hline$r_{1}$ & Half distance & $\mathrm{cm}$ & 0.304 & 0.198 & 0.227 & 0.489 \\
\hline$L_{o}$ & Initial root length & $\mathrm{cm} \mathrm{m}^{-3}$ & $4,162,621$ & $1,935,508$ & $1,371,549$ & 855,564 \\
\hline$k$ & Root growth rate & $\mathrm{cm} \mathrm{d}^{-1}$ & 8,484 & 10,506 & 10,306 & 4,641 \\
\hline
\end{tabular}

${ }^{\dagger}$ From Edwards and Huffman [18].

TABLE 3: Transport, sorption, and root parameters used in the NST 3.0 model to describe P uptake by smooth brome for the 0-120, 0-30, 30-60, and 60-120 cm soil depths.

\begin{tabular}{|c|c|c|c|c|c|c|}
\hline \multicolumn{2}{|c|}{ Parameter } & \multirow{2}{*}{$\frac{\text { Units }}{\mathrm{cm}^{2} \mathrm{~s}^{-1}}$} & \multirow{2}{*}{$\frac{0-120 \mathrm{~cm}}{8.9 E-6}$} & \multirow{2}{*}{$\frac{0-30 \mathrm{~cm}}{8.9 E-6}$} & \multirow{2}{*}{$\frac{30-60 \mathrm{~cm}}{8.9 E-6}$} & \multirow{2}{*}{$\frac{60-120 \mathrm{~cm}}{8.9 E-6}$} \\
\hline$D_{e}$ & Diffusion coefficient in water ${ }^{\dagger}$ & & & & & \\
\hline$\Theta$ & Volumetric soil water content & $\mathrm{cm}^{3} \mathrm{H}_{2} \mathrm{O} / \mathrm{cm}^{3}$ soil & 0.256 & 0.25 & 0.26 & 0.26 \\
\hline$f$ & Impedance factor & Unitless & 0.243 & 0.23 & 0.25 & 0.25 \\
\hline$V_{o}$ & Water uptake at root & $\mathrm{cm} \mathrm{s}^{-1}$ & $8.16 E-7$ & $8.16 E-7$ & $8.16 E-7$ & $8.16 E-7$ \\
\hline$C_{\mathrm{li}}$ & Initial solution concentration & $\mu \mathrm{mol} \mathrm{cm}{ }^{-3}$ & $1.141 E-2$ & $3.74 E-2$ & $2.58 E-3$ & $2.58 E-3$ \\
\hline$b$ & Buffer power & Unitless & 73 & 28 & 98 & 92 \\
\hline$I_{\max }$ & Maximum influx at high concentration & $\mu \mathrm{mol} \mathrm{cm}{ }^{-2} \mathrm{~s}^{-1}$ & $3.27 E-8$ & $3.27 E-8$ & $3.27 E-8$ & $3.27 E-8$ \\
\hline$K_{m}$ & Solution concentration when influx is $0.5 I_{\max }$ & $\mu \mathrm{mol} \mathrm{cm}{ }^{-3}$ & $2.71 E-5$ & $2.71 E-5$ & $2.71 E-5$ & $2.71 E-5$ \\
\hline$C_{\min }$ & Solution concentration when influx is zero & $\mu \mathrm{mol} \mathrm{cm}-3$ & $1.22 E-6$ & $1.22 E-6$ & $1.22 E-6$ & $1.22 E-6$ \\
\hline$r_{o}$ & Root radius & $\mathrm{cm}$ & 0.0114 & 0.0135 & 0.009 & 0.0117 \\
\hline$r_{1}$ & Half distance & $\mathrm{cm}$ & 0.505 & 0.255 & 0.347 & 0.914 \\
\hline$L_{o}$ & Initial root length & $\mathrm{cm} \mathrm{m}^{-3}$ & $2,486,379$ & $1,464,477$ & 793,155 & 228,747 \\
\hline$k$ & Root growth rate & $\mathrm{cm} \mathrm{d}^{-1}$ & 3,572 & 8,631 & 1,622 & 464 \\
\hline
\end{tabular}

${ }^{\dagger}$ From Edwards and Huffman [18]. 
holding all other parameters used in the model at the base level. Calculated estimates of uptake were compared with the base case value as a way of assessing whether a particular model parameter was more or less influential in determining the level of P uptake predicted by the model. One hundred and four model simulations were conducted for each of the three vegetation types in support of the sensitivity analyses.

To explore the uptake of $\mathrm{P}$ in the $0-30,30-60$, and 60 $120 \mathrm{~cm}$ soil depths, soil supply and root growth values were developed for each depth interval (Tables 1, 2, and 3). The water uptake rate and Michaelis-Menten kinetics values used in the $0-120 \mathrm{~cm}$ simulation for each cover type were assumed to represent uptake in each cover type for the three depth intervals.

\section{Results and Discussion}

Total estimated $\mathrm{P}$ uptake for the $126 \mathrm{~d}$ simulation period was $79.1 \mathrm{mmols} \mathrm{m}^{-3}$ for cottonwood, $69.5 \mathrm{mmols} \mathrm{m}^{-3}$ for switchgrass, and $61.0 \mathrm{mmols} \mathrm{m}^{-3}$ for smooth brome, all to a depth of $120 \mathrm{~cm}$. Using these rates of uptake as a base, estimates of uptake on a per hectare basis were calculated for buffers composed of various percentages of the three cover types (Table 4). Model estimates of $\mathrm{P}$ uptake over a single growing season ranged from $18.9 \mathrm{~kg} \mathrm{ha}^{-1}$ for the smooth brome only to $24.5 \mathrm{~kg} \mathrm{ha}^{-1}$ for cottonwood only (Table 4). Simulated buffers with mixtures of trees and grasses were intermediate to the pure stands noted above. Simulated uptake in a buffer composed of 50\% smooth brome and $50 \%$ switchgrass exceeded the uptake in a simulated smooth brome only buffer by $1.33 \mathrm{~kg} \mathrm{ha}^{-1}$, but was $1.29 \mathrm{~kg} \mathrm{ha}^{-1}$ less than a switchgrass only buffer.

Based on these simulations, the greatest amount of $\mathrm{P}$ is captured in a pure stand of cottonwood when compared to other buffer configurations. Assuming that this relationship holds for the longer term, the potential to capture and retain $\mathrm{P}$ on site is greater with the cottonwood given its longer lifespan and substantially larger level of standing biomass with the passage of time. The standing crop of the perennial grasses will come to relative equilibrium after a few years and the annual level of $\mathrm{P}$ intercepted will stabilize. If the grasses are removed annually, or even more frequently, the potential for $\mathrm{P}$ uptake will increase due to the fact that the level of $\mathrm{P}$ recycled annually by the standing vegetation will be reduced. The same would be true for the removal of the aboveground portion of the cottonwood, although it would be more practical to harvest the trees on a 7-to-10-year cycle as a fiber or fuel byproduct. For example, Kelly et al. [8] found that a total of $101 \mathrm{kgha}^{-1}$ of $\mathrm{P}$ would be removed over a 4 yr period from a mixed stand buffer compared to a $62 \mathrm{~kg}$ of $\mathrm{P} \mathrm{ha}^{-1}$ for a smooth brome control. Although a pure stand of cottonwood would be more effective in the capture of solution $\mathrm{P}$, it should be kept in mind that the grass communities will be more effective in retarding or preventing the loss of $\mathrm{P}$ due to soil erosion [29].

Each of the parameters used in the model was subjected to a single factor sensitivity analysis using the $0-120 \mathrm{~cm}$ and $0-30 \mathrm{~cm}$ values for each of the three cover type species.
Results indicated that four factors, $I_{\max }, k, r_{o}$ and $L_{o}$, were consistently responsive at both depths across species to changes ranging from $-50 \%$ to $+100 \%$. The response of each of these four parameters for each species is illustrated for the $0-120 \mathrm{~cm}$ analysis in Figure 1. All other parameters were either minimally responsive or nonresponsive to change at both intervals. As illustrated in Figure 1, the response to change in root growth rate $(k)$ was lower than those of the other three parameters. A doubling of the root growth rate increased $\mathrm{P}$ uptake by cottonwood by approximately $9 \%$ while the same change induced a $26 \%$ increase in switchgrass $\mathrm{P}$ uptake. Changes in root radius $\left(r_{o}\right)$ and initial root length $\left(L_{o}\right)$ had larger impacts on uptake estimates than did changes to the root growth rate (Figure 1). Comparison of the 0 $30 \mathrm{~cm}$ response to the $0-120 \mathrm{~cm}$ response produced essentially the same response pattern for both depth intervals. However, the $r_{o}$ response in the $0-120 \mathrm{~cm}$ sensitivity analysis was slightly more responsive to change than in the $0-30 \mathrm{~cm}$ simulations (data not shown). These results point to the importance of designing a sampling scheme that is capable of providing as accurate an estimate of the initial root length and mean root radius as possible since the model will be responsive to over or under estimates in either or both of these values.

As noted in Figure 1, the $I_{\max }$ value is the single most influential parameter in the model for all three of the test species. In all three cases, a $50 \%$ decrease or a $100 \%$ increase in $I_{\max }$ leads to an identical decrease or increase in estimated $\mathrm{P}$ uptake. As suggested earlier, this points to the fact that $\mathrm{P}$ supply in this soil exceeds the ability of all three of these species to take up $\mathrm{P}$, even when the maximum rate of uptake is doubled. If the goal is to capture as much solution phase $\mathrm{P}$ as possible, it will be useful to create additional demand through periodic harvests and removal of the $\mathrm{P}$ contained in the biomass. Additionally, it could be useful to screen other species to determine if they might have higher rates of $\mathrm{P}$ uptake and storage in accumulated biomass.

Values used to evaluate $\mathrm{P}$ uptake in each of the three depth intervals for each plant cover type are presented in Tables 1, 2, and 3. As noted above, it was assumed that the Michaelis-Menten uptake kinetics values $\left(I_{\max }, K_{m}, C_{\min }\right)$ and the water uptake rate at the root $\left(V_{o}\right)$ within a cover type would not vary as a function of soil depth interval. We cannot verify the validity of this assumption, and thus it should be considered as a reasonable first approximation. In future studies the collection of depth dependent values for these parameters would test the validity of this assumption and help refine future model applications. Soil supply and root geometry values were unique to the particular depth interval.

Model exploration of the level of $\mathrm{P}$ uptake as a function of soil depth indicated that in all three cover types the level of uptake was highest in the $0-30 \mathrm{~cm}$ intervals (Table 5) although the values ranged from $85 \%$ of total uptake for cottonwood to $56 \%$ of total uptake for switchgrass. A partial explanation for these differences in uptake can be found by comparing the root length values (Tables 1 and 2) for the $0-30 \mathrm{~cm}$ depth interval where $68 \%$ of the cottonwood root length occurs compared to $46 \%$ of the switchgrass 
TABLE 4: NST 3.0 model estimates of phosphorus uptake in kilograms per hectare to a depth of $120 \mathrm{~cm}$ over a $126 \mathrm{~d}$ growing season for buffers composed of varying percentages on an area basis of cottonwood, switchgrass, and smooth brome.

\begin{tabular}{|c|c|c|c|c|c|c|}
\hline \multirow{3}{*}{ Plant community } & \multicolumn{6}{|c|}{ Percentage contribution cottonwood/switchgrass/smooth brome } \\
\hline & $66 / 17 / 17$ & $33 / 33 / 33$ & $0 / 50 / 50$ & $100 / 0 / 0$ & $0 / 100 / 0$ & $0 / 0 / 100$ \\
\hline & \multicolumn{6}{|c|}{$\mathrm{kgPha}^{-1}$} \\
\hline Cottonwood & 16.3 & 8.1 & 0 & 24.5 & 0 & 0 \\
\hline Switchgrass & 3.6 & 7.1 & 10.8 & 0 & 21.5 & 0 \\
\hline Smooth brome & 3.2 & 6.2 & 9.4 & 0 & 0 & 18.9 \\
\hline$\Sigma$ & 23.1 & 21.4 & 20.2 & 24.5 & 21.5 & 18.9 \\
\hline
\end{tabular}

TABLE 5: NST 3.0 model estimates of phosphorus uptake in kilograms per hectare for four depth increments at the end of a $126 \mathrm{~d}$ simulated growing season for buffers composed of cottonwood, switchgrass, and smooth brome.

\begin{tabular}{|c|c|c|c|c|}
\hline \multirow{3}{*}{ Plant community } & \multicolumn{4}{|c|}{ Depth of soil increment $(\mathrm{cm})$} \\
\hline & $0-120$ & $0-30$ & $30-60$ & $60-120$ \\
\hline & \multicolumn{4}{|c|}{$\mathrm{kg} \mathrm{Pha}^{-1}$} \\
\hline Cottonwood & 24.5 & 20.4 & 2.7 & 0.8 \\
\hline Switchgrass & 21.5 & 15.3 & 7.3 & 4.7 \\
\hline Smooth brome & 21.4 & 18.8 & 5.4 & 2.0 \\
\hline
\end{tabular}

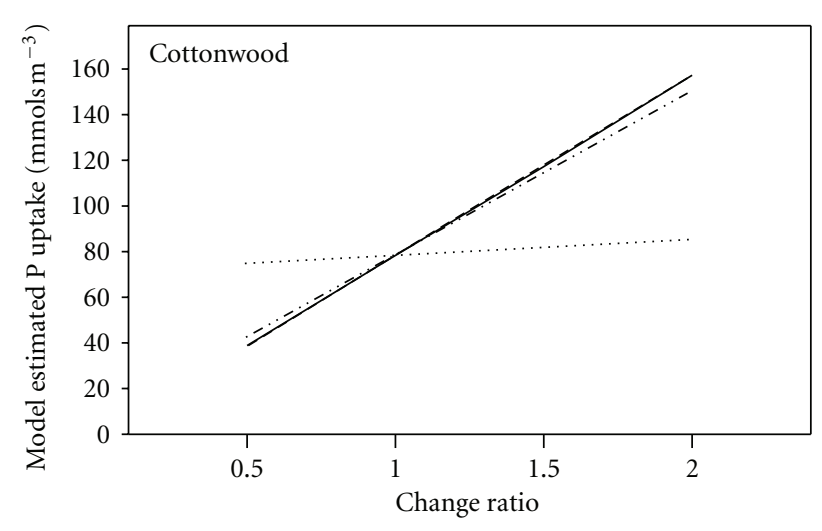

(a)

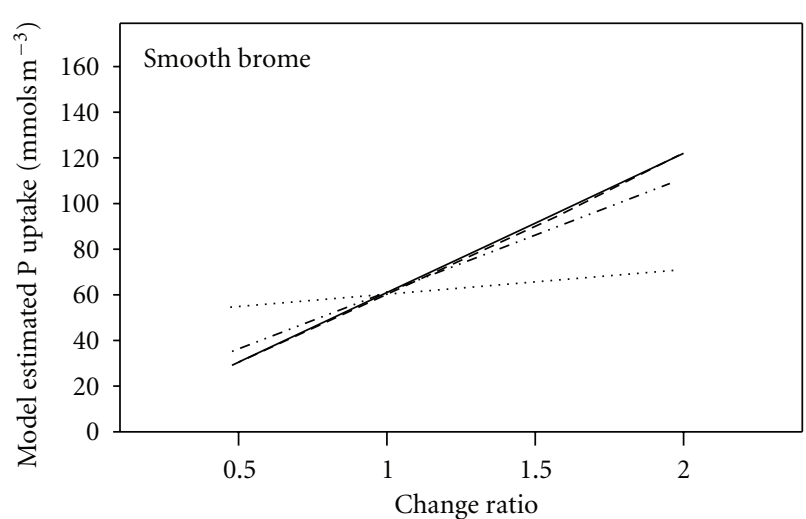

(b)

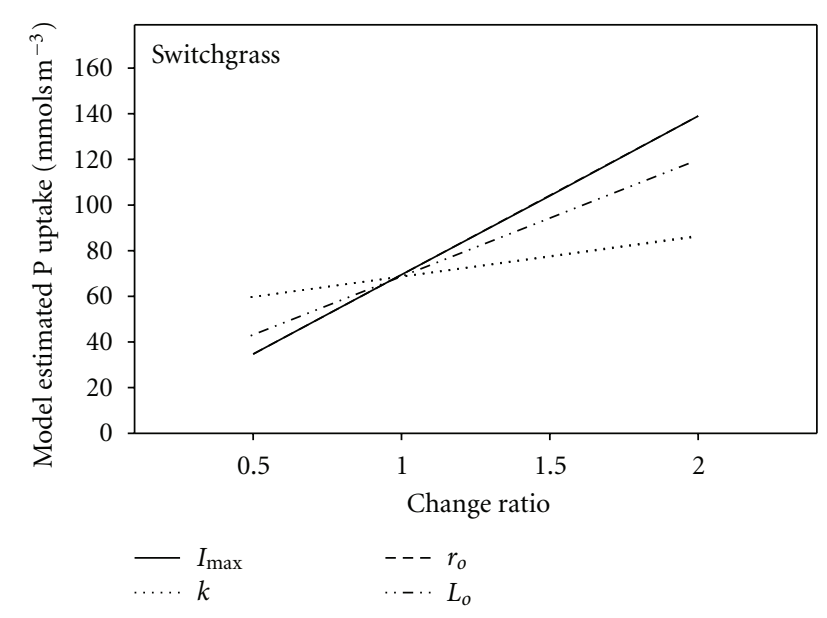

(c)

FIGURE 1: Sensitivity analysis of predicted P uptake by cottonwood, smooth brome, and switchgrass using the NST 3.0 model showing the effect on predicted $\mathrm{P}$ uptake of varying individually the maximum nutrient influx rate at high concentration $\left(I_{\max }\right)$, root growth rate $(k)$, root radius $\left(r_{o}\right)$, and initial root length $\left(L_{o}\right)$ values while holding all remaining model parameters constant. Each parameter has been varied from a $50 \%$ reduction ( 0.5 change ratio) to a doubling ( 2.0 change ratio). 


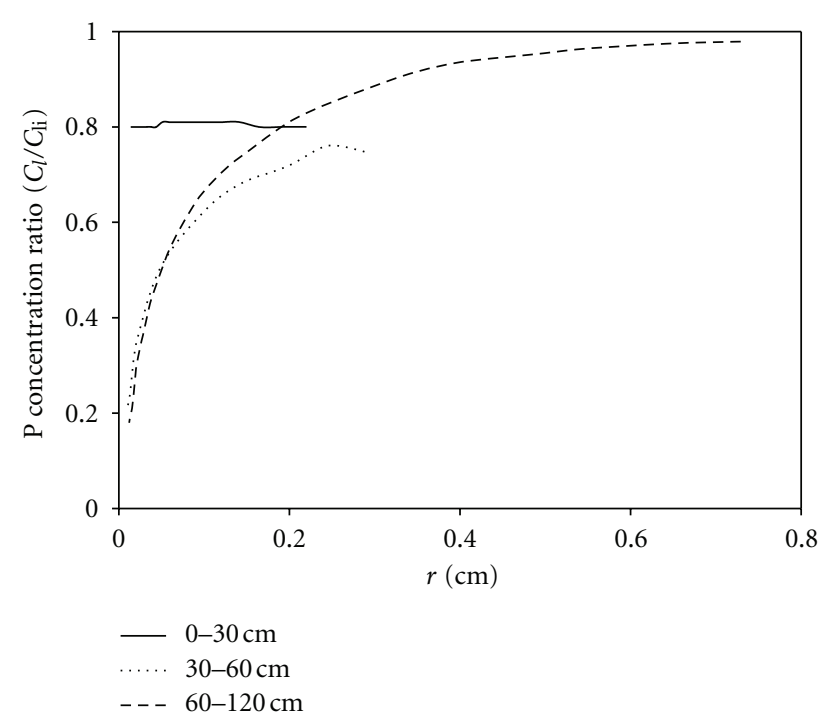

FIGURE 2: Effect of the distance from the root surface, as defined by the $r_{1}$ value, on the ratio of the final solution concentration to the initial solution concentration $\left(C_{l} / C_{\mathrm{li}}\right)$ of $\mathrm{P}$ for the $0-30,30-60$, and $60-120 \mathrm{~cm}$ soil depths in the smooth brome cover type.

root length. This is also consistent with the results of the sensitivity analysis with respect to the influence of increasing root length on $\mathrm{P}$ uptake (Figure 1). However, it is also important to note that $\mathrm{P}$ uptake is not totally a function of root length since switchgrass had the highest total root length (Table 2), but was second in total uptake and just barely exceeded the level of uptake by smooth brome which had only $59 \%$ of the total root length of switchgrass (Table 3 ).

If the amount of $\mathrm{P}$ uptake for each of the three depth intervals within a cover type is summed, the estimate of total uptake obtained for switchgrass and smooth brome as compared to the value obtained for the same two cover types in the $0-120 \mathrm{~cm}$ simulation (Table 5), increases by approximately $20 \%$ in both cases. A similar comparison of the cottonwood data reveals that the total by summation of the three layers is approximately $2 \%$ lower than the $0-120 \mathrm{~cm}$ simulation (Table 5). We speculate that the differences associated with the summed values may be attributable to small differences in the observed uptake-based approach used for the calculation of the Michaelis-Menten values, since previous studies have shown uptake to be particularly sensitive to changes in $I_{\max }$ values [30].

Figure 2 depicts solution $\mathrm{P}$ concentration in relation to the initial concentration as determined by the model for each of the three depth intervals in the smooth brome cover type at the end of 126 days of simulated uptake. The decline in solution $\mathrm{P}$ concentration in the surface layer is fairly uniform throughout the soil surrounding the root. A different pattern is seen in the concentration profiles for the 30-60 and 60$120 \mathrm{~cm}$ depths. Due to the slow rate of $\mathrm{P}$ diffusion through the soil and the relatively lower initial $\mathrm{P}$ concentration, a fairly steep gradient develops with much greater depletion of $\mathrm{P}$ near the root surface and a lower level of $\mathrm{P}$ depletion as distance from the root increases. In both the 30-60 and
60-120 simulations, the $\mathrm{P}$ concentration at the end of the simulation is approximately $80 \%$ lower than it was at the start of the simulation. Similar $C_{l} / C_{\mathrm{li}}$ ratio patterns were observed for the three depth intervals in the cottonwood and switchgrass simulations. These observations are consistent with the findings from several studies, as summarized by Hinsinger et al. [10], which attribute the formation of similar gradients to the relatively slow diffusion rate of $\mathrm{P}$ through the soil to the root surface with little or no contribution attributable to mass flow. However, Roose et al. [31] suggest that the numerical solution used in the NST 3.0 model has limitations when describing more complex roots systems. To address this concern, Roose and Kirk [32] explored the use of a simplified analytical solution that would more fully allow for both convection and diffusion. Their findings warrant further consideration as we continue the evolution and application of mechanistic nutrient uptake models.

\section{Conclusions}

Results of this study indicate that a simulation model such as NST 3.0 can provide both useful insights into the ability of various plant cover types to capture solution $\mathrm{P}$ and a means to explore which soil and plant factors are the most influential in predicting plant $\mathrm{P}$ uptake. A single factor sensitivity analysis for each cover type identified $I_{\max }, k, r_{o}$ and $L_{o}$ as the parameters having the most impact on model estimates of $\mathrm{P}$ uptake. This result indicates in this case that soil supply of $\mathrm{P}$ did not limit uptake. Model evaluation of $\mathrm{P}$ uptake as a function of soil layer indicated that in all three cover types uptake was highest from the 0-30 cm layer. Consequently, our hypothesis that subsoil uptake might play a proportionally greater role in total uptake by these deep rooted species was not supported by model predictions. Although results indicate a pure stand of cottonwood would be more effective in capturing solution $\mathrm{P}$, it should be kept in mind that the grass communities will be more effective in mitigating or preventing the loss of particulate $\mathrm{P}$ due to soil erosion. While the results of this study are most encouraging, recent evaluations of the current approaches to mechanistic modeling $[10,15,32]$ point to the need for a further evolution of the structure of minimalistic mechanistic nutrient uptake models. In the final analysis, it is important to remind ourselves that the validity of predictions produced by this or any model, is highly dependent on the quality of the data used to represent each of the parameters.

\section{Acknowledgments}

The authors express their appreciation to Robin Sokolowsky for assistance with data summarization and to Dr. J. K. Kelly for assistance with figure preparation. Preparation of this paper was supported by funds from the Virginia Agricultural Experiment Station and the Virginia Tech College of Natural Resources and Environment. 


\section{References}

[1] D. E. Radcliffe, J. Freer, and O. Schoumans, "Diffuse phosphorus models in the United States and Europe: their usages, scales, and uncertainties," Journal of Environmental Quality, vol. 38, no. 5, pp. 1956-1967, 2009.

[2] L. L. Burkitt, W. J. Dougherty, R. Corkrey, and S. T. Broad, "Modeling the risk of phosphorus runoff following single and split phosphorus fertilizer applications in two contrasting catchments," Journal of Environmental Quality, vol. 40, no. 2, pp. 548-558, 2011.

[3] C. C. Hoffmann, C. Kjaergaard, J. Uusi-Kämppä, H. C. B. Hansen, and B. Kronvang, "Phosphorus retention in riparian buffers: review of their efficiency," Journal of Environmental Quality, vol. 38, no. 5, pp. 1942-1955, 2009.

[4] R. P. Udawatta, H. E. Garrett, and R. Kallenbach, "Agroforestry buffers for nonpoint source pollution reductions from agricultural watersheds," Journal of Environmental Quality, vol. 40, no. 3, pp. 800-806, 2011.

[5] M. D. Tomer, T. B. Moorman, J. L. Kovar, D. E. James, and M. R. Burkart, "Spatial patterns of sediment and phosphorus in a riparian buffer in western Iowa," Journal of Soil and Water Conservation, vol. 62, no. 5, pp. 329-338, 2007.

[6] E. O. Young and R. D. Briggs, "Phosphorus concentrations in soil and subsurface water: a field study among cropland and riparian buffers," Journal of Environmental Quality, vol. 37, no. 1, pp. 69-78, 2008.

[7] C. van der Salm, W. J. Chardon, G. F. Koopmans, J. C. van Middelkoop, and P. A. I. Ehlert, "Phytoextraction of phosphorus-enriched grassland soils," Journal of Environmental Quality, vol. 38, no. 2, pp. 751-761, 2009.

[8] J. M. Kelly, J. L. Kovar, R. Sokolowsky, and T. B. Moorman, "Phosphorus uptake during four years by different vegetative cover types in a riparian buffer," Nutrient Cycling in Agroecosystems, vol. 78, no. 3, pp. 239-251, 2007.

[9] N. Claassen and B. Steingrobe, "Mechanistic simulation models for a better understanding of nutrient uptake from soil," in Mineral Nutrition of Crops: Fundamental Mechanisms and Implications, Z. Rengel, Ed., pp. 327-367, Food Products Press, New York, NY, USA, 1999.

[10] P. Hinsinger, A. Brauman, N. Devau et al., "Acquisition of phosphorus and other poorly mobile nutrients by roots. Where do plant nutrition models fail?" Plant and Soil, vol. 348, no. 1-2, pp. 29-61, 2011.

[11] N. Claassen, K. M. Syring, and A. Jungk, "Verification of a mathematical model by simulating potassium uptake from soil," Plant and Soil, vol. 95, no. 2, pp. 209-220, 1986.

[12] S. A. Barber and J. H. Cushman, "Nitrogen uptake model for agronomic crops," in Modeling Wastewater RenovationLand Treatment, I. K. Iskandar, Ed., pp. 382-409, WileyInterscience, New York, NY, USA, 1981.

[13] K. Oats and S. A. Barber, "Nutrient uptake: a minicomputer program to predict nutrient absorption from soil by roots," Journal of Agronomic Education, vol. 16, pp. 65-68, 1987.

[14] R. D. Hangs, J. D. Knight, and K. C. J. van Rees, "Nitrogen uptake characteristics for roots of conifer seedlings and common boreal forest competitor species," Canadian Journal of Forest Research, vol. 33, no. 1, pp. 156-163, 2003.

[15] W. Lin and J. M. Kelly, "Nutrient uptake estimates for woody species as described by the NST 3.0, SSAND, and PCATS mechanistic nutrient uptake models," Plant and Soil, vol. 335, no. 1, pp. 199-212, 2010.
[16] J. L. Kovar and N. Claassen, "Growth and phosphorus uptake of three riparian grass species," Agronomy Journal, vol. 101, no. 5, pp. 1060-1067, 2009.

[17] J. M. Kelly and T. Ericsson, "Assessing the nutrition of juvenile hybrid poplar using a steady state technique and a mechanistic model," Forest Ecology and Management, vol. 180, no. 1-3, pp. 249-260, 2003.

[18] O. W. Edwards and E. O. Huffman, "Diffusion of aqueous solutions of phosphoric acid at 25 ", Journal of Physical Chemistry, vol. 63, no. 11, pp. 1830-1833, 1959.

[19] N. Claassen and S. A. Barber, "A method for characterizing the relation between nutrient concentration and flux into roots of intact plants," Plant Physiology, vol. 54, no. 4, pp. 564-568, 1974.

[20] J. H. Edwards and S. A. Barber, "Nitrogen uptake characteristics of corn at low N concentration as influenced by plant age," Agronomy Journal, vol. 68, no. 1, pp. 17-19, 1976.

[21] D. Tennant, "A test of a modified line intercept method of estimating root length," Journal of Ecology, vol. 63, no. 3, pp. 995-1001, 1975.

[22] A. D. Mackay and S. A. Barber, "Effect of soil moisture and phosphate level on root hair growth of corn roots," Plant and Soil, vol. 86, no. 3, pp. 321-331, 1985.

[23] J. L. Kovar and S. A. Barber, "Phosphorus supply characteristics of 33 soils as influenced by seven rates of phosphorus addition," Soil Science Society of America Journal, vol. 52, no. 1, pp. 160-165, 1988.

[24] L. S. Clesceri, A. S. Greenberg, and R. R. Trussell, Standard Methods for the Examination of Water and Wastewater, American Public Health Association, Washington, DC, USA, 18th edition, 1995.

[25] R. A. Issac and J. D. Kerber, "Atomic absorption and flame photometry techniques and uses in soil, plant, and water analysis," in Instrumental Methods for Analysis of Soils and Plant Tissue, L. M. Walsh, Ed., pp. 17-37, Soil Science Society of America, Madison, Wis, USA, 1971.

[26] J. M. Kelly, S. A. Barber, and G. S. Edwards, "Modeling magnesium, phosphorus and potassium uptake by loblolly pine seedlings using a Barber-Cushman approach," Plant and Soil, vol. 139, no. 2, pp. 209-218, 1992.

[27] J. M. Kelly, A. H. Chappelka, and B. G. Lockaby, "Measured and estimated parameters for a model of nutrient uptake by trees," New Zealand Journal of Forest Science, vol. 24, pp. 213225, 1994.

[28] M. Silberbush and S. A. Barber, "Sensitivity of simulated phosphorus uptake to parameters used by a mechanisticmathematical model," Plant and Soil, vol. 74, no. 1, pp. 93100, 1983.

[29] A. N. Sharpley, B. H. Foy, and P. J. A. Withers, "Practical and innovative measures for the control of agricultural phosphorus losses to water: an overview," Journal of Environmental Quality, vol. 29, no. 1, pp. 1-9, 2000.

[30] S. A. Barber, Soil Nutrient Bioavailability, John Wiley \& Sons, New York, NY, USA, 2nd edition, 1995.

[31] T. Roose, A. C. Fowler, and P. R. Darrah, "A mathematical model of plant nutrient uptake," Journal of Mathematical Biology, vol. 42, no. 4, pp. 347-360, 2001.

[32] T. Roose and G. J. D. Kirk, "The solution of convectiondiffusion equations for solute transport to plant roots," Plant and Soil, vol. 316, no. 1-2, pp. 257-264, 2009. 

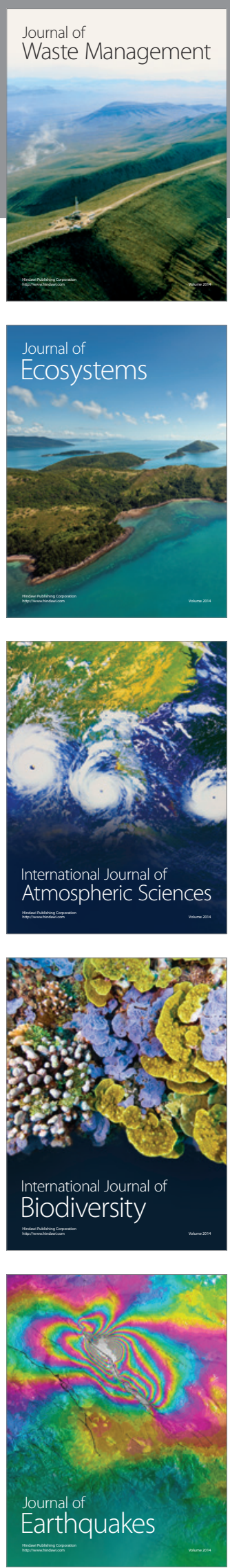
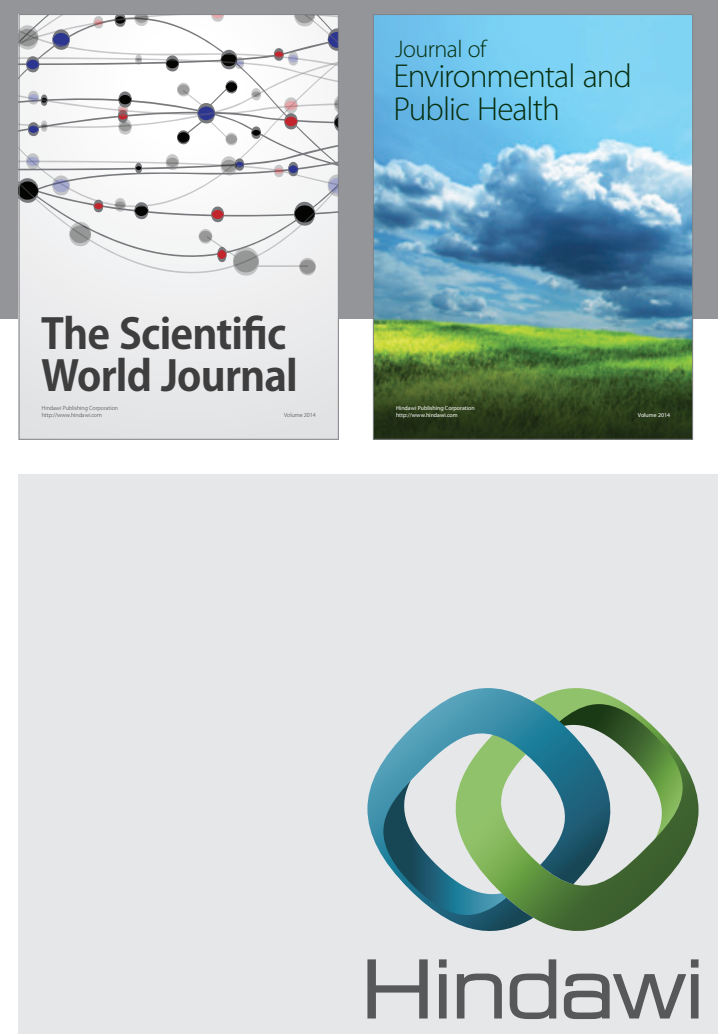

Submit your manuscripts at

http://www.hindawi.com
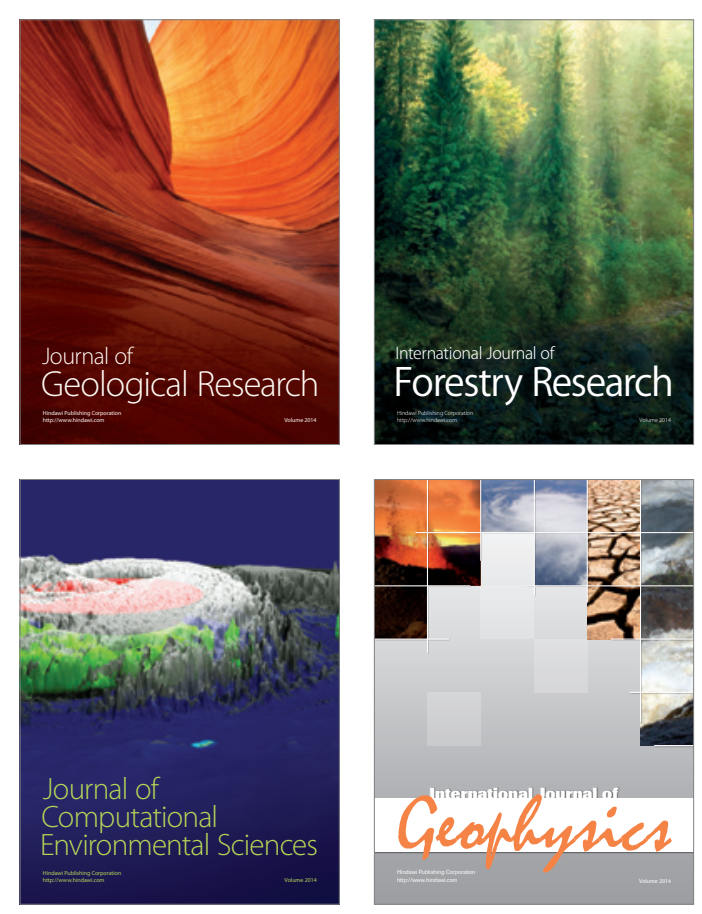
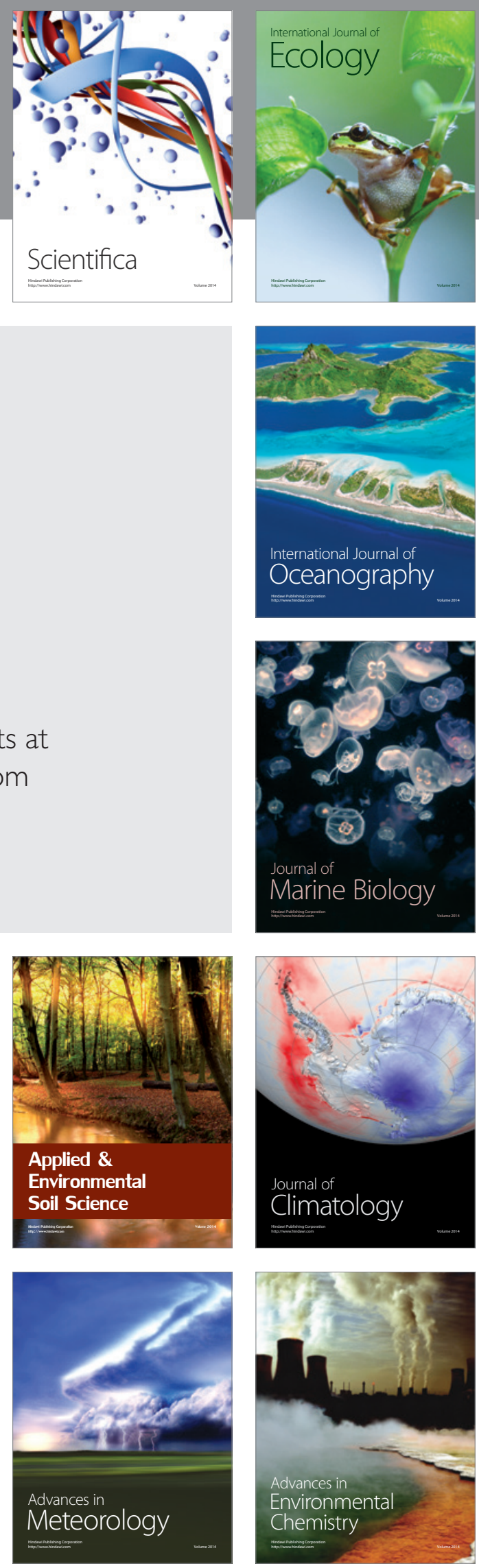